\title{
内蒙古地区羊草草原植被对温度变化的动态响应
}

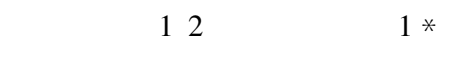 \\ (1 中国科学院植物研究所植被数量生态学重点实验室 北京 100093) \\ (2 中国气象局沈阳大气环境研究所, 沈阳 110016)
}

摘 要 $1981 \sim 1994$ 年连续 14 年内蒙古羊草草原温度随时间变化结果显示, 该区域温度变化具有不对称性, 冬季 最低均温升高明显, 而最高温及平均温度无明显增加趋势。羊草草原气候的变化主要表现在冬季最低温的增加, 而不是平均温度的增加。羊草群落的结构和功能对冬季最低均温变化的响应研究表明, 随着冬季最低均温的升 高, 阿尔泰狗哇花( Heteropappus altaicus) 和冰草 (Agropyron michnoi) 的重要值及地上初级生产力将明显增加, 而寸草 苔 (Cares duriuscula) 则呈下降趋势, 作为群落主要优势种的羊草 (Leymus chinensis) 和大针茅 (Stipa grandis) 及其它优 势植物对冬季最低均温变化反应不明显。同时, 群落的生物多样性指数 (Simpson 指数、Shannon-Wiener 指数)、物种 饱和度及地上初级生产力对冬季最低均温也均无显著相关, 14 年间冬季最低均温的变化并没有对群落的结构和功 能产生明显影响。然而, 因寸草苔和冰草等少数优势植物对冬季最低均温变化反应的敏感, 温度变化的幅度增加 或时间延续很可能造成少数优势种在群落中地位的改变, 进而可能导致羊草群落结构和功能的变化。这表明在进 行气候变化的模拟和模型研究时, 不能仅简单地考虑平均温度增加的情况, 而应确定主导影响因子,从而了解草原 生态系统对全球变化的响应, 选取适宜的模型参数。

关键词 羊草草原 冬季最低均温 重要值 地上初级生产力

\section{RESPONSE OF LEYMUS CHINENSIS GRASSLAND VEGETATION IN INNER MONGOLIA TO TEMPERATURE CHANGE}

\author{
WANG Yu-Hui ${ }^{12}$ and ZHOU Guang-Sheng ${ }^{1 *}$ \\ (1 Laboratory of Quantitative Vegetation Ecology, Institute of Botany , Chinese Academy of Sciences, Beijing 100093 , China) \\ (2 Institute of Atmospheric Environment, China Meteorological Administration, Shenyang 110016 , China)
}

\begin{abstract}
Global temperatures are increasing, and, in particular, global minimum temperatures are increasing faster than maximum temperatures. Because temperature is a key factor hat controls the growth and distribution of vegetation , and there is no a priori reason to assume that ecosystems will respond similarly to changes in minimum and maximum temperatures, it is very important to explore the ecological consequences of global warming on terrestrial communities.

The Leymus chinensis grassland is a dominant ecosystem of Inner Mongolia , and this region is very vulnerable to global climate change. We analyzed a long term climate and vegetation data base (1981 - 1994) for Inner Mongolia to examine the characteristics and the ecological consequences of temperature changes on Leymus chinensis grasslands. The results showed that temperatures increased and minimum temperatures, especially winter minimum temperatures, increased faster than maximum and average temperatures. There were no significant relationships between winter minimum temperatures and diversity indices (Simpson index and Shannonwiener index), species saturation, and aboveground net primary productivity ( ANPP) at the community scale. At the species level , the importance value and ANPP of most species had no significant relationship with winter minimum temperatures, except for Agropyron michnoi, Heteropappus altaicus and Carex duriuscula, all of which showed significant negative relationships. Because these are important species in this grassland community, the results suggest that the structure and function of the L. chinensis grassland community could be altered if winter minimum temperatures continue to increase. Thus, the identification of key elements of temperature change is very important for understanding and predicting the impacts of global warming to L. chinensis grassland communities.
\end{abstract}

Key words Winter minimum temperature, Leymus chinensis grassland, Importance value , ANPP 
以全球变暖为重要标志的全球变化及由此引起 的一系列生态安全问题已成为不争的事实。20世 纪全球平均温度增加了 $0.6{ }^{\circ} \mathrm{C}$ 左右 ( IPCC ,1996) ,中 国上升了 $0.4 \sim 0.5{ }^{\circ} \mathrm{C}$ (秦大河等,2002) ; 预计 2100 年将比 1990 年全球平均温度还要增加 $1.4 \sim 5.8$ ${ }^{\circ} \mathrm{C}$ 。温度作为控制植被生长和分布的关键环境因素 之一, 它的变化必将对自然生态系统的结构和功能 产生深刻影响。目前国际上众多学者采用原状土植 被移栽于不同海拔高度、人工温室、土壤加热等模拟 实验以及模型模拟等不同的方法对全球增温对陆地 生态系统可能产生的影响开展了大量的研究 (Herik et al. , 2001 ; Carter 1996 ; Oleksyn et al. , 1998 ; Krankina et al .,1997) 结果表明全球增温可导致植 被生产力和土壤呼吸增大 ( Jenkinson et al.,1991; Kirschbaum ,1995) ,C 4 植物丰富度增加（White et al . , 2000), 并会改变陆地生态系统的养分循环速率 (Peng \& Apps ,1998) 及碳源-汇关系( Smith \& Shugart , 1993 ; Oechel et al .,2000)。我国学者就全球变暖对 植被生长、光合作用、生产力、养分和水分利用效率、 调落物分解和土壤碳储量的影响也开展了大量的研 究。如周华坤等 (2000)采用国际冻原计划模拟增温 的方法研究了温度升高对矮嵩草 (Kobresia humilis) 草甸的物候、群落结构和地上生物量的影响。杨永 辉等 $1997 ; 2002)$ 分别采用原状土植被在不同海拔 高度移植的方法研究了英格兰北部山地草原和太行 山植被生产力、土壤水分和养分状况对温度升高的 反应。王其兵等 $(2000 \mathrm{a} ; 2000 \mathrm{~b})$ 研究了气候变暖对 草原植被凋落物分解和土壤氮素矿化作用的影响。 同时我国学者也利用模型研究预测了全球气候变暖 对我国植被的影响 (周广胜等,1996; 延晓东等, 2000a 2000b; 肖向明等 ,1996)。

然而, 目前有关植物对全球变暖响应的研究, 无 论是模拟实验还是模型研究, 主要关注的是平均温 度或白天温度升高对陆地生态系统的影响。但是已 有观测表明全球增温具有不对称性, 其中冬季增温 比夏季增温明显; 目最低温比最高温增加更高, 全球 许多地区日温差减小 (IPCC ,2001a)。最低温升高一 方面会导致植物及微生物夜间呼吸强度增加, 而另 一方面又可能通过延长植物生长季而提高植被生产 力及固碳能力 (Alward et al.,1999)。因此, 要想了 解和探讨植被结构和功能对全球变暖的响应, 仅着 眼于植被对平均温度或白天温度增加的反应还是远 远不够的,自然生态系统对最低温变化响应的研究 仍然十分缺乏。为了准确认识和模拟陆地生态系统
对全球变化的响应, 预测陆地生态系统的发展趋势， 十分有必要继续开展陆地植被对全球不对称增温， 特别是最低温升高的响应研究。

为此, 本文选取对全球变化敏感、并具有重要经 济价值的内蒙古地区羊草草原作为研究对象, 利用 $1981 \sim 1994$ 年连续 14 年的气象和植被资料, 分析温 度 (最低温、最高温和平均温)的变化特征, 揭示影响 草原植物群落的主导温度因子, 进而阐明其对于羊 草草原优势植物种的重要值、地上初级生产力以及 群落的多样性指数 (Simpson 指数、Shannon-wiener 指 数)、均匀度和物种饱和度的影响, 为探讨羊草草原 生态系统对全球变化的响应机理、准确地预测羊草 草原在全球气候变化下的发展趋势提供借鉴与依 据。

\section{1 研究区域概况}

研究区域位于内蒙古锡林河流域, 是内蒙古高 原中部与大兴安岭南段西侧山地遥相接触的地带, 在自然地理上属于温带内蒙古草原区典型草原栗钙 土亚区。地理位置为北纬 $43^{\circ} 26^{\prime} \sim 44^{\circ} 39^{\prime}$, 东经 $115^{\circ}$ $32^{\prime} \sim 117^{\circ} 12^{\prime}$ 。本区地势东南高西北低, 属大陆性温 带半干旱气候, 年均温为 $-1.4 \sim 2.0^{\circ} \mathrm{C}$ 。冬季寒冷 干燥, 夏季温暖湿润, $3 \sim 5$ 月常有大风。土壤为栗 钙土, 植被以羊草 (Leymus chinensis)、大针茅 (Stipa grandis) 等典型草原植被为主。本流域大部分地区 的天然牧草 4 月上、中旬返青,9月中、下旬停止生 长, 生长期达 150 160 d 左右(李博等, 1988)。

\section{2 研究方法}

本研究采用羊草草原长期固定围栏样地的 $1981 \sim 1994$ 年植被调查资料及同期气象资料进行分 析。羊草长期固定样地设在白音锡勒牧场益和乌垃 分场的锡林河二级阶地与丘陵坡麓之间，地势微倾 斜, 地表较平整, 土壤为典型栗钙土。植被以羊草、 大针茅、 $\square$ 草 ( Koeleria cristata)、冰草 (Agropyron cristatum) 等旱生禾草为主。固定样地自 1979 年围 封后一直未加利用。植被调查样方面积为 $1 \mathrm{~m} \times 1$ $\mathrm{m}, 20$ 个重复; 主要调查内容包括植物种类、分种密 度、频度、分种地上生物量, 调查时间为每年生长季 的 5 月 15 日 $\sim 9$ 月 15 日，每隔 $15 \mathrm{~d}$ 测定 1 次。地上 生物量采用收割法, 分种齐地剪割, 实验室烘干 65 ${ }^{\circ} \mathrm{C}$ ) 称重 (精度 $0.1 \mathrm{~g}$ )。采集所获地上生物量的最高 值为当年羊草草原植物群落初级生产力。所有植被 调查资料由内蒙古大学刘钟龄教授提供。历年气象 
资料从锡林浩特市气象站获取。

\section{3 数据分析}

群落植物的重要值、生物多样性指数即 Shannon-Wiener 指数 $(H)$ 和 Simpson 指数 $(D)$ 以及均匀度 ( $C$ ) 计算公式如下 $($ Peet ,1974)：

(1) 重要值 $(I V)$ :

重要值 $(I V)$

$=\frac{\text { 相对密度 }+ \text { 相对生物量 }+ \text { 相对频度 }}{3} \times 100$

(2) 多样性指数采用 Shannon-Wiener 指数 $(H)$ 和 Simpson 指数 $(D)$ :

$H=-\sum P_{i} \ln P_{i}$

$D=1 / \Sigma P_{i}{ }^{2}$

式中, $P_{i}$ 为第 $i$ 个物种个体 (或生物量、重要值 等) 所占样方总个体数 (或生物量、重要值等) 比值。 本研究依据重要值进行相关计算。

(3) 均匀度指数 $(C)$ :

$C=H / \ln S$

式中, $S$ 为物种数目, $H$ 为 Shannon-Wiener 多样 性指数。

相关关系分析采用 SPSS 统计软件 (11.5 版)。

\section{4 结果与分析}

4.1 温度年际变化特征

为了了解羊草草原温度随时间的变化状况，采
用一元回归方法分析 $1981 \sim 1994$ 年连续 14 年, 不 同时期平均温度、最高温度和最低温度与时间的回 归关系(表 1)。在分析过程中根据羊草草原植物的 实际生长状况及当地的气候特点, 考虑了全年温度 (1月～12 月)、有效温度 (前一年 10 月～当年 8 月)、春季温度 ( 3 月～5 月)、夏季温度 ( 6 月～8 月)、 冬季温度(前一年 12 月 当年 2 月)和秋季温度 (前 一年 9 月～前一年 11 月)。由表 1 的分析结果可以 看出在连续 14 年间冬季最低温度、年均最低温以及 有效最低温均在波动中呈增加趋势, 其中冬季最低 温增加最为明显, 年均增温 $0.37{ }^{\circ} \mathrm{C}(p=0.007, R=$ $0.68)$; 有效最低温年均增加 $0.137{ }^{\circ} \mathrm{C}(p=0.028, R$ $=0.58)$;年均最低温年均增加 $0.136{ }^{\circ} \mathrm{C}(p=0.028$, $R=0.59$ ) (图 1)。而其它时间的最低温以及最高温 和平均温均与时间无显著相关。这一结果表明, 在 $1981 \sim 1994$ 年连续 14 年间全球变暖在该区域最突 出地表现是冬季最低温度的增加, 这与当前全球变 化的有关研究结果相似(IPCC ,2001a；2001b；Harvell et al . 2002)。而全年最低温与有效最低温的增加 很可能与冬季最低温明显增加有关。因为分析结果 显示春、夏、秋 3 季的最低温均没有出现明显的增 加。值得指出的是最低温呈现逐渐升高的趋势并不 是明显的直线关系, 是一个波动式上升的过程。

4.2 冬季最低温增加对优势物种的影响 锡林河流域的羊草草原是以多年生根茎禾草羊

表 1 不同时期平均温度、最高温度和最低温度与时间的回归分析

Table 1 Regressive relationship between time and average temperature , maximum temperature and minimum temperature

\begin{tabular}{|c|c|c|c|}
\hline $\begin{array}{l}\text { 时间 } \\
\text { Time }\end{array}$ & $\begin{array}{c}\text { 一元回归方程 } \\
\text { Simple linear regression }\end{array}$ & $\begin{array}{c}\text { 显著度 } \\
\text { Significant }(p)\end{array}$ & $\begin{array}{l}\text { 复相关系数 }\left(R^{2}\right) \\
\text { Coefficient square }\end{array}$ \\
\hline 年均温 Average annual temperature & $T_{\text {ave-a }}=-142.17+0.073$ year & 0.164 & 0.155 \\
\hline 有效均温 Average effective temperature & $T_{\text {ave-e }}=-169.57+0.086$ year & 0.107 & 0.202 \\
\hline 春季均温 Average spring temperature & $T_{\text {ave-sp }}=-45.24+0.025$ year & 0.739 & 0.010 \\
\hline 夏季均温 Average summer temperature & $T_{\text {ave-su }}=37.95-0.009$ year & 0.852 & 0.003 \\
\hline 秋季均温 Average fall temperature & $T_{\text {avef }}=-256.56+0.13$ year & 0.140 & 0.172 \\
\hline 冬季均温 Average winter temperature & $T_{\text {ave-w }}=-488.60+0.237$ year & 0.076 & 0.239 \\
\hline 年最高温 Annual maximum temperature & $T_{\text {max-a }}=-132.40+0.071$ year & 0.251 & 0.108 \\
\hline 有效最高温 Effective maximum temperature & $T_{\text {max-e }}=-98.91+0.053$ year & 0.373 & 0.067 \\
\hline 春季最高温 Spring maximum temperature & $T_{\max -s p}=24.98-0.008$ year & 0.921 & 0.001 \\
\hline 夏季最高温 Summer maximum temperature & $T_{\text {max-su }}=36.40-0.006$ year & 0.920 & 0.001 \\
\hline 秋季最高温 Fall maximum temperature & $T_{\max -\mathrm{f}}=-92.94+0.051$ year & 0.640 & 0.019 \\
\hline 冬季最高温 Winter maximum temeperature & $T_{\text {max-w }}=-415.80+0.203$ year & 0.111 & 0.198 \\
\hline 年最低温 Annual minimum temperature & $T_{\text {min-a }}=-276.61+0.136$ year & $0.028^{*}$ & 0.341 \\
\hline 有效最低温 Effective minimum temperature & $T_{\text {min-e }}=-301.22+0.148$ year & $0.028^{*}$ & 0.342 \\
\hline 春季最低温 Spring minimum temperature & $T_{\text {min-sp }}=-107.39+0.051$ year & 0.366 & 0.069 \\
\hline 夏季最低温 Summer minimum temperature & $T_{\text {min-su }}=-56.93+0.034$ year & 0.561 & 0.029 \\
\hline 秋季最低温 Fall minimum temperature & $T_{\min -\mathrm{f}}=-252.94+0.124$ year & 0.227 & 0.119 \\
\hline 冬季最低温 Winter minimum temperature & $T_{\min -\mathrm{w}}=-759.52+0.369$ year & $0.007^{*}$ & 0.464 \\
\hline
\end{tabular}



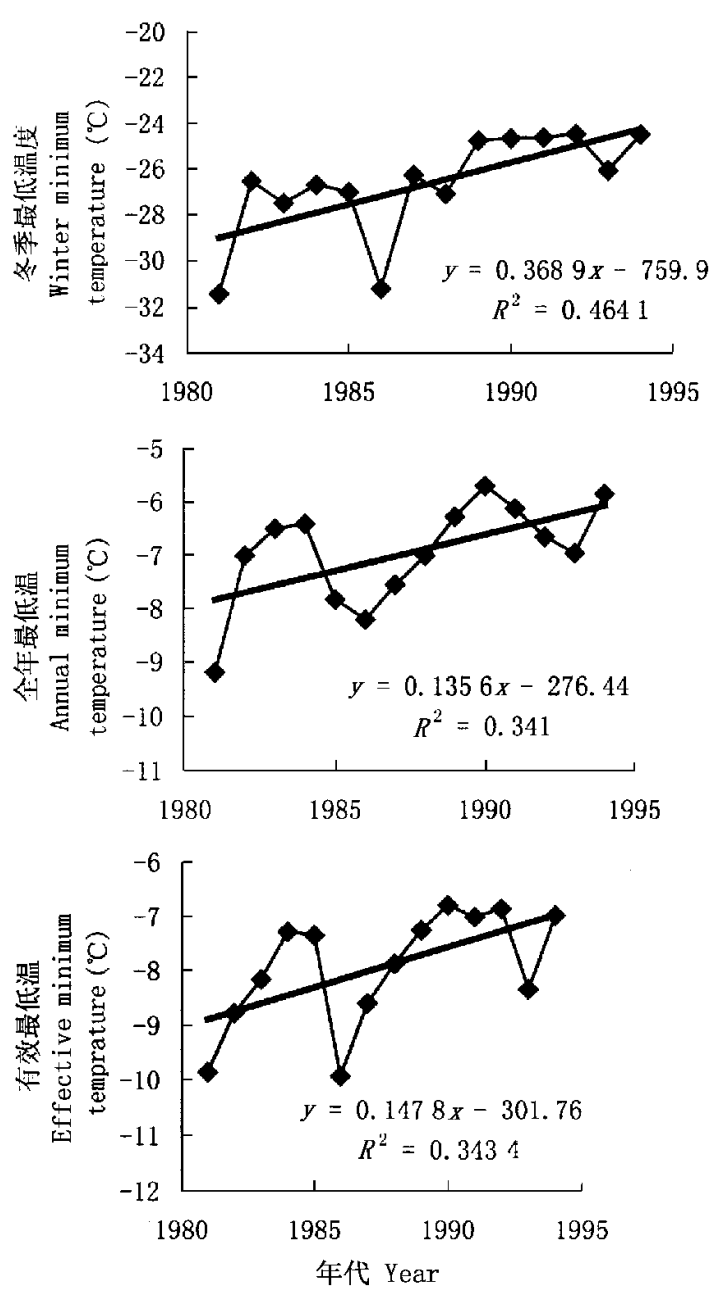

图 1 最低温度的年际变化

Fig. 1 Changes of minimum temperature

草和丛生禾草大针茅为主要建群种的温带典型草 原。1981 1994 年连续 14 年间调查样方共记录高 等植物 79 种, 分属于 23 个科。根据记录种在群落 中的重要值以及对群落不同层片的代表性, 分析了 羊草草原 11 种优势植物种对冬季最低均温变化的 响应。这 11 种优势植物的年均重要值之和约为群 落总重要值的 $71.77 \%$ ，不同年际间 11 种优势植物 重要值呈现波动性变化(表 2)，按其年均重要值大 小分别为羊草、大针茅、寸草苔 (Carex duriuscula)、西 伯利亚羽茅 (Achnatberum sibiricum)、冰草、变蒿 (Artemisia commutata)、小叶锦鸡儿 ( Caragana microphylla)、口草、䊁隐子草 (Cleistogenes aquarrosa)、阿尔 泰狗哇花 ( Heteropappus altaicus)、冷蒿 (Artemisia frigi$d a)$ 。在群落中占最主要地位的是羊草, 其次为大针 茅、寸草苔、西伯利亚羽茅和冰草, 其年均重要值之 和占群落总重要值的 $56.1 \%$ 。

羊草草原 11 种优势植物种地上净初级生产力
的变化与其重要值的变化相似, 也呈现出年际间波 动的趋势, 而且波动幅度大于重要值 (表 3)。按照 每个种地上初级生产力的多年平均值, 其顺序为羊 草、大针茅、西伯利亚羽茅、变蓠、小叶锦鸡儿、冰草、 寸草苔、口草、䊁隐子草、阿尔泰狗哇花和冷蕎。其 中, 羊草、大针茅、西伯利亚羽茅、变蒿、小叶锦鸡儿 对群落地上初级生产力的贡献最为突出, 约占总地 上净初级生产力的 $71.29 \%$ 。

为了了解冬季最低温度变化是否会对 11 种优 势植物产生影响, 进一步采用 Spearman 相关分析方 法对冬季最低温与各优势种的重要值、地上初级生 产力的相关关系进行了分析。结果表明冬季最低温 度的变化与阿尔泰狗哇花、寸草苔及冰草在群落中 的地位与作用密切相关。其中阿尔泰狗哇花的重要 值及地上初级生产力与冬季最低温均呈极显著正相 关 $(p<0.001)$; 冰草的重要值和地上初级生产力与 冬季最低温呈显著正相关 $(p<0.05)$; 而寸草苔的重 要值和地上初级生产力与冬季最低温呈显著负相关 $(p<0.05)$ 。这表明在冬季最低温增加的情况下, 阿 尔泰狗哇花、寸草苔在羊草群落的生产力和结构组 成中的作用将逐渐增加, 而冰草的作用则将逐步减 弱。但是作为群落最主要优势植物的羊草和大针茅 以及其它优势植物一一西伯利亚羽茅、冷蒿、小叶锦 鸡儿、糙隐子草、口草、变蒿的重要值、地上初级生产 力均与冬季最低温变化无显著相关关系 (表 4)。这 说明当前冬季最低温的变暖幅度不会对羊草草原主 要优势植物产生明显影响, 尽管少数优势植物种的 重要值和地上初级生产力对冬季最低温的变化比较 敏感。

由于植物的生长和变化不仅受到温度的影响而 且还与生境的土壤条件和降水等因素密切相关。特 别在干旱半干旱的草原地区,降水具有十分重要的 作用 (牛建明 ,2001; Boutton et al. , 1988 ; Briggs \& Knapp , 1995 ; Deshmukh，1984)。由于研究样地长期 围封 微环境相对一致。在没有人为干扰和大的土 壤侵蚀发生的情况下, 土壤性状的改变相对于温度 和降水的变化是缓慢而比较稳定的。因此，在时间 相对短 (14 年) 的情况下, 可以认为温度和水分是控 制羊草草原植物生长的更重要的因子。为了判断 11 种优势植物对冬季最低温度变化的响应是否受 到同期降水变化的影响, 进一步采用 Spearman 相关 分析方法对冬季降水量与各优势种的重要值、地上 初级生产力的相关关系进行了分析 (表 5), 并与冬 季最低温度与各优势种的重要值、地上初级生产力 
表 2 羊草草原优势植物种重要值变化

Table 2 Changes of predominant species' important values in Leymus chinensis grassland

\begin{tabular}{|c|c|c|c|c|c|c|c|c|c|c|c|c|c|c|c|}
\hline \multirow{2}{*}{$\begin{array}{l}\text { 物种 } \\
\text { Species }\end{array}$} & \multicolumn{14}{|c|}{ 年代 Year } & \multirow{2}{*}{$\begin{array}{c}\text { 均值 } \pm \text { 标准误 } \\
\text { Mean } \pm \text { standard error }\end{array}$} \\
\hline & 1981 & 1982 & 1983 & 1984 & 1985 & 1986 & 1987 & 1988 & 1989 & 1990 & 1991 & 1992 & 1993 & 1994 & \\
\hline 羊草 Leymus chinensis & 32.41 & 35.03 & 25.42 & 31.42 & 30.25 & 22.70 & 16.54 & 27.80 & 19.41 & 35.45 & 22.78 & 23.39 & 19.34 & 29.75 & $26.55 \pm 1.621$ \\
\hline 针茅 Stipa grandis & 10.82 & 8.24 & 9.63 & 8.17 & 10.27 & 14.91 & 14.89 & 12.56 & 12.94 & 9.61 & 13.51 & 10.11 & 14.51 & 9.52 & $11.41 \pm 0.646$ \\
\hline 寸草苔 Carex duriuscula & 8.09 & 9.02 & 8.69 & 8.14 & 8.71 & 8.65 & 12.85 & 8.32 & 4.23 & 2.65 & 2.31 & 2.72 & 5.29 & 6.92 & $6.90 \pm 0.814$ \\
\hline 西伯利亚羽茅 Achnatberum sibiricum & 7.35 & 4.19 & 3.86 & 4.26 & 4.54 & 6.60 & 8.22 & 7.51 & 9.19 & 6.55 & 6.36 & 3.79 & 5.64 & 9.05 & $6.22 \pm 0.506$ \\
\hline 冰草 Agropyron michnoi & 2.87 & 2.54 & 8.86 & 3.68 & 2.26 & 2.16 & 3.84 & 1.31 & 10.93 & 2.69 & 8.94 & 7.13 & 6.94 & 6.09 & $5.02 \pm 0.823$ \\
\hline 变蕎 Artemisia commutata & 2.40 & 6.97 & 1.92 & 1.95 & 4.20 & 8.71 & 6.80 & 5.83 & 3.00 & 0.20 & 3.34 & 8.33 & 5.98 & 2.19 & $4.41 \pm 0.714$ \\
\hline 小叶锦鸡儿 Caragana microphylla & 0.67 & 3.40 & 6.87 & 0.43 & 0.00 & 2.90 & 3.50 & 5.25 & 10.80 & 3.91 & 4.69 & 0.23 & 4.89 & 5.22 & $3.77 \pm 0.791$ \\
\hline 口草 Koeleria cristata & 2.42 & 2.75 & 2.00 & 1.90 & 2.68 & 3.19 & 2.65 & 2.55 & 2.09 & 0.30 & 2.59 & 4.17 & 3.06 & 1.87 & $2.45 \pm 0.231$ \\
\hline 糙隐子草 Cleistogenes aquarrosa & 0.20 & 2.77 & 5.03 & 0.29 & 0.00 & 2.74 & 3.30 & 2.65 & 2.76 & 1.61 & 2.16 & 1.88 & 2.72 & 3.35 & $2.25 \pm 0.369$ \\
\hline 阿尔泰狗哇花 Heteropappus altaicus & 0.00 & 0.19 & 0.11 & 1.11 & 0.30 & 0.11 & 0.60 & 0.32 & 3.61 & 2.13 & 1.53 & 5.91 & 1.88 & 2.03 & $1.42 \pm 0.446$ \\
\hline 冷蒿 Artemisia frigida & 1.20 & 0.74 & 0.72 & 1.89 & 2.16 & 2.16 & 2.06 & 0.93 & 0.41 & 0.33 & 1.36 & 1.57 & 3.40 & 0.12 & $1.36 \pm 0.243$ \\
\hline
\end{tabular}

表 3 羊草草原优势植物种地上初级生产力 $\left(\mathrm{g} \mathrm{m}^{-2} \mathrm{a}^{-1}\right)$ 变化

Table 3 Changes of predominant species' aboveground net primary productivity $\left(\mathrm{g} \mathrm{m}^{-2} \mathrm{a}^{-1}\right)$ in Leymus chinensis grassland

\begin{tabular}{|c|c|c|c|c|c|c|c|c|c|c|c|c|c|c|c|}
\hline \multirow{2}{*}{$\begin{array}{c}\text { 物种 } \\
\text { Species }\end{array}$} & \multicolumn{14}{|c|}{ 年代 Year } & \multirow{2}{*}{$\begin{array}{c}\text { 均值 } \pm \text { 标准误 } \\
\text { Mean } \pm \text { Standard error }\end{array}$} \\
\hline & 1981 & 1982 & 1983 & 1984 & 1985 & 1986 & 1987 & 1988 & 1989 & 1990 & 1991 & 1992 & 1993 & 1994 & \\
\hline 羊草 Leymus chinensis & 125.68 & 3115.73 & 38.65 & 87.21 & 72.66 & 38.76 & 35.29 & 72.09 & 20.75 & 74.90 & 32.56 & 42.52 & 35.88 & 53.17 & $60.42 \pm 8.59$ \\
\hline 针茅 Stipa grandis & 76.14 & 43.71 & 23.34 & 29.36 & 38.54 & 54.54 & 61.80 & 63.56 & 33.32 & 42.25 & 46.69 & 35.83 & 68.21 & 30.69 & $46.28 \pm 4.32$ \\
\hline 西伯利亚羽茅 Achnatberum sibiricum & 38.17 & 12.81 & 5.68 & 9.48 & 10.46 & 14.89 & 24.02 & 24.87 & 15.68 & 18.00 & 14.55 & 7.09 & 12.72 & 26.02 & $16.75 \pm 2.36$ \\
\hline 变蒿 Artemisia commutata & 4.71 & 40.42 & 2.23 & 5.30 & 14.07 & 33.43 & 28.42 & 24.81 & 3.34 & 0.05 & 4.24 & 29.20 & 20.72 & 4.76 & $15.41 \pm 3.66$ \\
\hline 小叶锦鸡儿 Caragana microphylla & 3.11 & 15.09 & 15.90 & 1.53 & 0.00 & 7.29 & 12.04 & 21.59 & 28.14 & 11.41 & 15.16 & 0.61 & 16.63 & 11.97 & $11.46 \pm 2.21$ \\
\hline 冰草 Agropyron michnoi & 8.03 & 4.14 & 10.30 & 9.48 & 3.43 & 2.51 & 7.98 & 2.79 & 12.58 & 4.96 & 15.73 & 17.06 & 16.36 & 10.22 & $8.97 \pm 1.36$ \\
\hline 寸草苔 Carex duriuscula & 10.46 & 10.50 & 5.43 & 7.20 & 8.52 & 4.75 & 8.40 & 7.61 & 1.00 & 1.72 & 1.11 & 2.60 & 4.83 & 6.02 & $5.72 \pm 0.87$ \\
\hline 口草 Koeleria cristata & 1.65 & 2.64 & 0.61 & 2.51 & 3.67 & 4.61 & 4.50 & 4.02 & 1.09 & 0.08 & 4.43 & 8.93 & 5.09 & 1.86 & $3.26 \pm 0.61$ \\
\hline 糙隐子草 Cleistogenes aquarrosa & 0.56 & 5.44 & 10.01 & 0.61 & 0.00 & 3.10 & 4.18 & 3.41 & 1.66 & 0.88 & 1.65 & 1.96 & 2.81 & 4.71 & $2.93 \pm 0.70$ \\
\hline 阿尔泰狗哇花 Heteropappus altaicus & 0.00 & 0.01 & 0.06 & 1.09 & 0.64 & 0.05 & 0.83 & 0.88 & 4.15 & 1.57 & 0.63 & 21.61 & 1.38 & 2.39 & $2.52 \pm 1.50$ \\
\hline 冷蒿 Artemisia frigida & 1.88 & 0.42 & 0.35 & 1.74 & 3.50 & 3.44 & 2.20 & 0.67 & 0.23 & 0.32 & 1.16 & 2.32 & 7.52 & 0.02 & $1.84 \pm 0.54$ \\
\hline
\end{tabular}

表 4 主要优势植物重要值、地上初级生产力与冬季最低温度的相关系数

Table 4 Coefficient between important value , aboveground net primary productivity and winter minimum temperature

\begin{tabular}{|c|c|c|c|c|}
\hline & \multicolumn{2}{|c|}{$\begin{array}{c}\text { 重要值与冬季最低温 } \\
\text { Important value and winter minimum temperature }\end{array}$} & \multicolumn{2}{|c|}{$\begin{array}{c}\text { 地上初级生产力与冬季最低温 } \\
A N P P \text { and winter minimum temperature }\end{array}$} \\
\hline & $\begin{array}{l}\text { 相关系数 } \\
\text { Coefficient }\end{array}$ & $\begin{array}{c}\text { 显著性水平 } \\
\text { Significant level }\end{array}$ & $\begin{array}{l}\text { 相关系数 } \\
\text { Coefficient }\end{array}$ & $\begin{array}{c}\text { 显著性水平 } \\
\text { Significant level }\end{array}$ \\
\hline 小叶锦鸡儿 Caragana microphylla & 0.138 & 0.637 & 0.064 & 0.829 \\
\hline 冷蒿 Artemisia frigida & -0.262 & 0.366 & -0.266 & 0.358 \\
\hline 冰草 Agropyron michnoi & $0.543^{*}$ & 0.045 & $0.604^{*}$ & 0.022 \\
\hline 羊草 Leymus chinensis & -0.16 & 0.584 & -0.354 & 0.215 \\
\hline 大针茅 Stipa grandis & -0.152 & 0.605 & -0.288 & 0.318 \\
\hline 西伯利亚羽茅 Achnatberum sibiricum & 0.024 & 0.935 & -0.055 & 0.852 \\
\hline 粘隐子草 Cleistogenes aquarrosa & 0.112 & 0.703 & 0.029 & 0.923 \\
\hline$\square$ 草 Koeleria cristata & -0.051 & 0.864 & 0.152 & 0.605 \\
\hline 变蒿 Artemisia commutata & -0.015 & 0.958 & -0.116 & 0.692 \\
\hline 阿尔泰狗哇花 Heteropappus altaicus & $0.908^{* *}$ & 0.0001 & $0.749^{* *}$ & 0.002 \\
\hline 寸草苔 Carex duriuscula & $-0.622^{*}$ & 0.018 & $-0.538^{*}$ & 0.047 \\
\hline
\end{tabular}

* : 同表 1 See Table $1 \quad * *: p<0.01$

的相关系数进行了比较。结果表明冬季同期降水与 11 种优势植物的重要值和地上净初级生产力相关 性十分不明显，仅阿尔泰狗哇花的重要值和地上净 初级生产力与冬季降水具有显著相关, 相关系数分 别为 $0.553(p=0.04)$ 和 $0.542(p=0.045)$,而且相
关系数小于与冬季最低温度的相关系数。这一结果 表明可以排除同期降水对 11 种优势植物重要值和 地上净初级生产力对冬季最低温度响应的影响。

4.3 冬季最低温增加对羊草草原群落的影响 植物群落的结构和功能是群落特征的重要表 
现。通过对 1981 1994 年连续 14 年调查样方的多 样性指数、种饱和度、均匀度以及地上初级生产力的 计算结果表明, 不同年际间羊草群落的 ShannonWiener 指数和均匀度指数变化幅度较小, 分别在 2.6 $\sim 2.94$ 和 $0.70 \sim 0.80$ 之间, 而 Simpson 指数、物种饱 和度以及地上初级生产力在年际间的波动较大, 分 别在 $6.6 \sim 11.87 、 14.8 \sim 21.4$ 以及 $129.24 \sim 331.44$ 之间。进一步利用 Spearman 相关分析对冬季最低
温与群落的生物多样性指数、物种饱和度、均匀度以 及地上初级生产力的相关关系进行分析 结果表明, 仅均匀度指数与冬季最低温呈显著相关关系, 而相 关系数也仅为 $0.55(p=0.043)$ 。其它特征值与冬 季最低温均没有显著相关关系(表 6)。这表明当前 冬季最低温度升高的幅度不会对羊草植物群落的结 构和功能产生明显影响。

表 5 主要优势植物重要值、地上初级生产力与冬季降水的相关系数

Table 5 Coefficient between important values , aboveground net primary productivity and winter precipitation

\begin{tabular}{|c|c|c|c|c|}
\hline & \multicolumn{2}{|c|}{$\begin{array}{c}\text { 重要值与冬季最低温 } \\
\text { Important value and winter minimum temperature }\end{array}$} & \multicolumn{2}{|c|}{$\begin{array}{c}\text { 地上初级生产力与冬季最低温 } \\
A N P P \text { and winter minimum temperature }\end{array}$} \\
\hline & $\begin{array}{l}\text { 相关系数 } \\
\text { Coefficient }\end{array}$ & $\begin{array}{c}\text { 显著性水平 } \\
\text { Significant level }\end{array}$ & $\begin{array}{l}\text { 相关系数 } \\
\text { Coefficient }\end{array}$ & $\begin{array}{c}\text { 显著性水平 } \\
\text { Significant level }\end{array}$ \\
\hline 小叶锦鸡儿 Caragana microphylla & 0.132 & 0.652 & 0.132 & 0.652 \\
\hline 冷蒿 Artemisia frigida & -0.121 & 0.680 & 0.002 & 0.994 \\
\hline 冰草 Agropyron michnoi & 0.200 & 0.492 & 0.344 & 0.229 \\
\hline 羊草 Leymus chinensis & -0.013 & 0.964 & -0.051 & 0.863 \\
\hline 大针茅 Stipa grandis & -0.055 & 0.852 & 0.192 & 0.512 \\
\hline 西伯利亚羽茅 Achnatberum sibiricum & 0.178 & 0.542 & 0.172 & 0.557 \\
\hline 粘隐子草 Cleistogenes aquarrosa & -0.225 & 0.440 & -0.286 & 0.321 \\
\hline 口草 Koeleria cristata & 0.033 & 0.911 & -0.059 & 0.840 \\
\hline 变蒿 Artemisia commutata & -0.042 & 0.887 & -0.203 & 0.487 \\
\hline 阿尔泰狗哇花 Heteropappus altaicus & $0.553^{*}$ & 0.040 & $0.542^{*}$ & 0.045 \\
\hline 寸草苔 Carex duriuscula & -0.463 & 0.096 & -0.220 & 0.449 \\
\hline
\end{tabular}

* : 同表 1 See Table 1

表 6 羊草草原群落特征与冬季最低温度的相关系数

Table 6 Coefficient between characteristics of Leymus chinensis grassland and winter minimum temperature

\begin{tabular}{lccccc}
\hline & $\begin{array}{c}\text { Shannon-Wiener 指数 } \\
\text { Shannon-Wiener index }\end{array}$ & $\begin{array}{c}\text { Simpson 指数 } \\
\text { Simpson index }\end{array}$ & $\begin{array}{c}\text { 均匀度 } \\
\text { Evenness }\end{array}$ & $\begin{array}{c}\text { 种饱和度 } \\
\text { Species saturation }\end{array}$ & $\begin{array}{c}\text { 地上初级生产力 } \\
A N P P\end{array}$ \\
\hline 相关系数 Coefficient & 0.191 & 0.248 & 0.547 & -0.112 & -0.209 \\
显著性水平 Significant level & 0.513 & 0.392 & 0.043 & 0.703 & 0.474 \\
\hline
\end{tabular}

\section{5 结 论}

当前,气候变暖已成为全球性问题 ( IPCC, 2001b）, 了解全球及不同区域的气候变化对人类赖 以生存的陆地生态系统可能产生的影响已成为全球 变化研究关注的焦点之一。气候变暖不仅会通过温 度直接对陆地生态系统产生深刻影响，而且还会通 过影响其它环境因素对陆地生态系统产生间接作 用。全球变暖并不是一个均匀变化过程, 存在着最 低温度比最高温度、冬季温度比夏季温度升高明显 的特征( IPCC, 2001a)。特别是, 我们目前还没有充 足的证据表明 植物对最低或最高温度变化的响应 与其对平均温度变化的响应相同 (Alward et al.,
1999 ; Boden et al , 1994 ; Easterling et al , 1997)。 Alward 等 (1999) 利用连续 23 年的观测资料研究表 明 科罗拉多东北部草原主要优势种和功能群的丰 富度以及地上初级生产力受最低温度变化的影响明 显，一些敏感种的变化已经导致草原抵御干旱和放 牧干扰的能力有所降低。因此, 了解全球气候变暖 的趋势和程度, 重视研究区域各气候因子的变化特 征, 弄清温度变化, 特别是温度的不对称变化对于植 物的影响机理是理解植物对全球变化的响应及制定 应对策略的关键。

根据对地处全球变化最为明显和敏感区域的我 国内蒙古地区的羊草草原 1981 1994 年连续 14 年 的温度资料分析表明, 该区域的温度变化与全球温 度变化相一致, 具有明显的不对称性。最低温度, 特 
别是冬季最低均温呈现波动式上升趋势, 而最高温 及平均温度则没有明显增加趋势。李镇清等 (2003) 利用该区域连续 20 年的气象资料的研究也证实该 区域温度具有变暖的趋势。这表明全球变暖对内蒙 古羊草草原气候的影响主要体现在冬季最低温度的 增加方面, 而不是如以往研究假设的平均温度的增 加(肖向明等 ,1996 王其兵等 ,2000a；2000b)。

进一步对内蒙古地区羊草草原 1981～1994 年 连续 14 年主要优势种的重要值、地上初级生产力以 及群落的生物多样性指数、均匀度、种饱和度以及地 上初级生产力与冬季最低均温的相关关系分析表 明, 羊草草原的优势植物一一阿尔泰狗哇花、寸草苔 以及冰草对冬季最低均温变化反应敏感,而作为主 要群落优势种及建群种的羊草和大针茅以及其它优 势植物, 如西伯利亚羽茅、冷蒿、小叶锦鸡儿、糙隐子 草、口草、变蒿对冬季最低均温的变化反应却不明 显。另外, 从群落的尺度上看, 14 年间研究区域物 种组成和地上初级生产力变化与冬季最低均温的变 化并没有显著的关系, 温度变化的幅度还没有对羊 草草原植物群落的结构和功能产生明显影响。但这 并不意味着全球变暖不会对羊草草原未来发展趋势 产生作用:相反, 该研究表明如果这一变化趋势长期 继续下去将对羊草草原的群落与结构产生影响。对 优势种的重要值分析结果已经表明, 占群落总重要 值 $11.92 \%$ 的寸草苔和冰草随着冬季最低均温的升 高, 其重要值将呈现明显的减少或增加的趋势。如 果冬季最低均温升高的幅度增加或时间延续, 很可 能寸草苔和冰草在羊草群落中的作用将发生改变, 从而对群落的结构和功能产生影响。

研究亦表明, 内蒙古羊草草原区的气候变化的 确存在着不对称的变化, 而且少数优势植物种对此 的反应还比较敏感。因此, 在研究与模拟羊草草原 对气候变化的响应时不仅要研究平均温度变化的影 响，而且亦应关注各气候因子变化特征，如最低温度 和最高温度等对羊草草原可能产生的影响, 以确定 影响草原群落的主导因子, 准确地模拟草原生态系 统对全球变化的响应。

\section{参 考 文 献}

Alward, R.D., J. K. Detling \& D. G. Milchunas. 1999. Grassland vegetation changes and nocturnal global warming. Science, 283 : $229 \sim 231$.

Boden, T. A., P. D. Kaiser, R. J. Sepanski \& F. W. Stoss. 1994. ORNL/CDIAC-65 carbon dioxide information analysis center. Oak ridge national laboratory. Oak Ridge, TN, $686 \sim 736$. Boutton, T.W., L. L. Tieszen \& S. K. Imbamba. 1988. Biomass dynamics of grassland vegetation in Kenya. African Journal of Ecology, 26:89 101.

Briggs, J.M. \& A.K. Knapp. 1995. Interannual variability in primary production in tallgrass prairie. Journal of Range Management, 29: 19 23 .

Carter, K. K. 1996. Provenance tests as indicators of growth response to climate change in 10 north temperate tree species. Canadian Journal of Forest Research, 26: 1089 1095.

Deshmukh, I.K. 1984. A common relationship between precipitation and grassland peak biomass for east and southern Africa. African Journal of Ecology, 22:181 186 .

Easterling, D. R., B. Horton, P. D. Jones \& T. C. Peterson. 1997. Maximum and minimum temperature trends for the global. Science, 277:364 367 .

Harvell, C. D. , C. E. Mitchell, J. R. Ward, S. Altizer, A. P. Dobson, R. S. Ostfeld \& M.D. Samuel. 2002. Climate warming and disease risks for terrestrial and marine biota. Science, 296: $2158 \sim 2162$.

Herik, S., G. R. C. Melin, J. фystein, G. R. Michael \& V. George. 2001. Tree and forest functioning in response to global warming. New Phytologist, 149:369 400.

IPCC. 1996. Climate change 1995: the science of climate change. Cambridge, U.K. : Cambridge University Press. 133.

IPCC. 2001a. Climate change 2001: the scientific basis. Summary for policymakers and technical summary of the working group I report. Cambridge, U.K. : Cambridge University Press. 98.

IPCC. 2001b. Climate change 2001: the scientific basis. Contribution of working group I to the third assessment report of the intergoverrmental panel on climate change. Cambridge, United Kingdom and New York, NY, USA: Cambridge University Press. 881 .

Jenkinson, D.S., D.E. Adams \& A.Wild. 1991. Model estimates of $\mathrm{CO}_{2}$ emissions from soil in response to global warming. Nature, 351: $304 \sim 306$.

Kirschbaum, M. U.F. 1995. The temperature dependence of soil organic matter decomposition and the effect of global warming on soil organic C storage. Soil Biology and Biochemistry, 27:753 760 .

Krankina, O. N., R. K. Dixon, A. P. Kirilenko \& K. I. Kobak. 1997. Global climate change adaptation: examples from Russian boreal forests. Climatic Change, 36:197 215 .

Li, B. (李博), S.P. Yong(雍世鹏) \& Z.H. Li(李忠厚) . 1988. The vegetation of the Xilin river basin and its utilization. Research on Grassland Ecosystem (草原生态系统研究), 3:84 183. (in Chinese with English abstract)

Li, Z.Q. (李镇清), Z.G. Liu (刘振国), Z.Z. Chen (陈佐 忠) \& Z.G. Yang (杨宗贵). 2003. The effects of climate changes on the productivity in the Inner Mongolia steppe of China. Acta Prataculturae Sinica(草业学报), 12:4 10. (in Chinese with English abstract)

Niu, J.M. (牛建明). 2001. Impacts prediction of climatic change on distribution and production of grassland in Inner Mongolia. Acta Agrestia Sinica (草地学报), 9: $277 \sim 282$. (in Chinese with English abstract)

Oechel, W.C., G. L. Vourlitis, S. J. Hastings, R. Zulueta, L. D. Hinzman \& D. Kane. 2000. Acclimation of ecosystem $\mathrm{CO}_{2}$ exchange in the Alaskan Arctic in response to decadal climate warming. Nature, 406:978 981.

Oleksyn, J., M. G. Tjoelker \& P. B. Reich. 1998. Adaptation to changing environment in Scots pine populations across a latitudinal gradient. Silva Fennica, 32:129 140. 
Peet, R. K. 1974. Measurement of species diversity. Annual Review of Ecology and Systematics, 5:285 307.

Peng, C. H. \& M. J. Apps. 1998. Simulating carbon dynamics along the Boreal Forest Transect Case Study (BFTCS) in central Canada I. Sensitivity to climate change. Global Biogeochemical Cycles, 12: $393 \sim 402$.

Qin, D.H. (秦大河), Y.H.Ding (丁一汇), S.W. Wang (王 绍武), S. M. Wang (王苏民), G. R. Dong (董光荣), E. D. Lin (林而达)，C. Z. Liu (刘春蓁)，Z. X. She (会之 祥), H. N. Sun (孙蕙南), S. R. Wang (王守荣) \& G. H. $\mathrm{Wu}$ (伍光和). 2002. A study of environment change and its impacts in western China. Earth Science Frontiers (地学前缘), 9: $321 \sim 327$. (in Chinese with English abstract)

Smith, T. M. \& H. H. Shugart. 1993. The transient response of terrestrial carbon storage to a perturbed climate. Nature, 361: $523 \sim 526$

Wang, Q. B. (王其兵), L.H. Li (李凌浩), Y.F. Bai (白永 飞) \& X.R. Xing (邢雪荣). 2000a. Effects of simulated climate change on the decomposition of mixed litter in three steppe communities. Acta Phytoecologica Sinica (植物生态学报), 24:674 679. (in Chinese with English abstract)

Wang, Q. B. (王其兵), L.H. Li (李凌浩), Y.F. Bai (白永 飞) \& X.R. Xing (邢雪荣) . 2000b. Field experimental studies on the effects of climate change on nitrogen mineralization of meadow steppes soil. Acta Phytoecologica Sinica (植物生态学 报), 24:687 692. (in Chinese with English abstract)

White, T. A., B. D. Campbell, P. D. Kemp \& C. L. Hunt. 2000. Sensitivity of three grassland communities to simulated extreme temperature and rainfall events. Global Change Biology, 6: $671 \sim 684$.

Xiao, X.M. (肖向明), Y.F. Wang (王义凤) \& Z.Z. Chen (陈 佐忠). 1996. Dynamics of primary productivity and soil organic matter of typical steppe in the Xinlin river basin of Inner mongolia and their response to climate change. Acta Botanica Sinica(植物 学报), 38: 45 52. (in Chinese with English abstract)

Yan, X. D. (延晓冬), C. B. Fu (符淙斌) \& H. H. Shugart. 2000a. Simulating the effect of climate change on Xiaoxing' an Mountain forests. Acta Phytoecologica Sinica (植物生态学报), 24: $234 \sim 241$. (in Chinese with English abstract)

Yan, X. D. (延晓冬), S. D. Zhao (赵士洞),Z.L. Yu (于振 良). 2000b. Modeling growth and succession of Northeastern China forests and its applications in global change studies. Acta Phytoecologica Sinica(植物生态学报), 24: 1 8. (in Chinese with English abstract)

Yang, Y.H. (杨永辉), Z.P. Wang (王智平), Yasuo Sakura, C. Y. Tang(唐常源) \& Shizuo Shindo. 2002. Effects of global warming on productivity and soil moisture in Taihang Mountain: a transplant study. Chinese Journal of Applied Ecology (应用生态 学报), 13:667 671. (in Chinese with English abstract)

Yang, Y. H. (杨永辉), A. F. Harrison \& P. Ineson. 1997. Biomass response to a simulated global warming by changing of elevation and fertilizer addition in upland grassland. Acta Phytoecologica Sinica (植物生态学报), 21: $234 \sim 241$. (in Chinese with English abstract)

Zhou, G.S. (周广胜) \& X.S. Zhang (张新时). 1996. Study on NPP of natural vegetation in China under global climate change. Acta Phytoecologica Sinica(植物生态学报), 38: 8 17. (in Chinese with English abstract)

Zhou, H.K. (周华坤), X.M. Zhou(周兴民) \& X.Q. Zhao(赵 新全). 2000. A preliminary study on the influence of simulated greenhouse effect on a Kobresia humilis meadow. Acta Phytoecologica Sinica (植物生态学报), 24: $547 \sim 553$. (in Chinese with English abstract) 